\title{
Multinodular interdigitating plantar fibroma: A case study and literature review
}

\author{
Colin T. Graney ${ }^{* 1}$ and Marcus A. Baxter ${ }^{1}$ \\ ${ }^{1}$ Baylor Scott \& White Memorial Hospital, 2601 Thornton Lane Temple, TX 76502, USA
}

\begin{abstract}
Plantar fibromas are a common soft tissue mass that is frequently encountered by a foot and ankle surgeon. Plantar fibromas are typically thought of as a benign, firm, single or multinodular mass within the plantar fascia. There are several additional medical conditions that have been said to be affiliated with plantar fibromas including Dupuytren's contracture, Peyronie's disease, and even epilepsy. Plantar fibromas have been well documented in the past regarding surgical versus nonsurgical treatment as well as complications due to a high recurrence rate. The purpose of this case study and literature review is to evaluate the tumor staging in regards to surgical complications, imaging, recurrence, and histological findings upon excision, as well as present a rare case of an advanced interdigitating multinodular plantar fibroma.
\end{abstract}

\section{Introduction}

Plantar fibromas have been well described in the literature regarding a typical appearance, however there have been several varying opinions about the treatment and classification about the common soft tissue tumors. The first report of surgical excision for plantar fibromatosis occurred in 1822 by Sir Astley Cooper [1] where he would release the fascia and splint the digit to hold the release and prevent recurrence, but it wasn't until 50 years later where Madelung first reported an isolated mass and this disease became known as Ledderhose disease [2]. The involvement of a plantar fascial tumor was previously believed to be a component of a Dupuytren's diathesis including multiple sites in the body most notably the hand, penis, and knuckle pad [3]. More commonly Dupuytren's contracture is referred to as a palmar fascial cord thickening that may result in a mass or contracture of a digit. Peyronie's disease, like Dupuytren's contracture involves the underlying fascia, however results in a bend or curve of the penis [4].

An isolated plantar fibroma has been shown to be frequently benign, possibly bilateral thickening of the plantar fascia. Rarely the mass can become locally invasive affecting the surrounding fat, muscle, skin, and even neurovascular structures $[5,6]$. Men are affected more frequently than women and the lesions are most common between the ages of 50$60[7,8]$. Family history can include familial bowel cancers, polyposis coli, alcoholism, as well as epileptics currently on phenytoin $[9,10]$. Epilepsy treated with phenytoin may exhibit a higher occurrence due the drug's ability to inhibit cellular production of collagenase by $50 \%$ $60 \%$ [10]. Although primarily a clinical diagnosis several differential diagnoses (Table 1) can be considered. Clinical history as well as the progression of the lesion and remote locations of potential masses may play a critical role in the proper and rapid diagnosis.

Plantar fibromas will typically present as a palpable, well adhered, slowly enlarging, firm to rubbery, nontransilluminating mass on the plantar foot $[11,12]$. These masses have been described to have the potential to extend into the intermetatarsal components of the forefoot as well as into the tarsal cana [13]. These types of plantar fibromas can be a more aggressive variant of a plantar fibroma or have the term desmoplastic fibroma [11]. Allen subdivided classes of fibromatoses which included desmoplastic fibromatosis and defined it as an aggressive, large, deep seated, musculo-aponeurotic mass [14]. Clinically the mass is nonpainful, however the mass can become a space occupying lesion causing neural irritation leading to paresthesias [9]. Enneking, et al. described a classification system that discussed the aggressiveness of the mass into three stages regarding the location (Table 2) [12]. Haedicke clarified the natural history of the disease into three stages, including a proliferative, active (Involutional), and residual phase (Table 3) [3].

Imaging of the mass has been recommended and evaluated by Morrison, et al. stating plantar fibromas will have an expected location

Table 1. Differential diagnoses for soft tissue masses of the foot

\begin{tabular}{|c|c|c|c|c|}
\hline Lipoma & Inclusion Cyst & Fibrosarcoma & Neurolemmoma & Ganglion \\
\hline Neurofibroma & Callosity & Chondroma & Cicatrix / Keloid & Melanoma \\
\hline Leiomyoma & Rhabdomyosarcoma & $\begin{array}{c}\text { Clear cell } \\
\text { Sarcoma }\end{array}$ & $\begin{array}{c}\text { Synovial } \\
\text { Sarcoma }\end{array}$ & Liposarcoma \\
\hline $\begin{array}{c}\text { Giant cell } \\
\text { tumor of } \\
\text { tendon sheath }\end{array}$ & Rheumatoid nodule & $\begin{array}{c}\text { Granuloma } \\
\text { annulare }\end{array}$ & Sporotrichosis & $\begin{array}{c}\text { Sweat gland } \\
\text { Carcinoma }\end{array}$ \\
\hline
\end{tabular}

Table 2. Enneking staging of plantar fibromas.

\begin{tabular}{|c|c|}
\hline Stage & Location \\
\hline Stage I & Mass limited to one pedal compartment \\
\hline Stage II & Developmental phase with discrete lesion in the fascia \\
\hline Stage III & $\begin{array}{c}\text { High-grade tumor with extra-compartmental extension and skip lesions. } \\
\text { Locally infiltrative. }\end{array}$ \\
\hline
\end{tabular}

Correspondence to: Colin T. Graney, DPM, Baylor Scott \& White Memorial Hospital, 2601 Thornton Lane Temple, TX 76502, USA Tel: (469) 387-7569, E-mail: colin.graney@bswhealth.com; ctgraney@gmail.com

Key words: plantar fibroma, recurrence, foot

Received: March 07, 2017; Accepted: March 16, 2017; Published: March 20 2017 
Table 3. Natural history of mass formation

\begin{tabular}{|c|c|}
\hline Phase & Process \\
\hline Proliferative & Fibroblasts, cellular proliferation, perivascular round cell infiltration \\
\hline $\begin{array}{c}\text { Active } \\
\text { (Involutional) }\end{array}$ & Nodule, multinodule formation \\
\hline Residual & Collagen maturation, tissue contracture \\
\hline
\end{tabular}

within the fascia and be visualized as a nonencapsulated, heterogeneous, possibly multilobular mass [14]. Plantar fibromas will have a signal intensity that is unique to few malignancies, however $4 \%$ of malignant lesions can present similar to a plantar fibroma. The most notorious malignant neoplasm to be similar to a plantar fibroma in appearance is the clear cell sarcoma [14].

Treatment of plantar fibromatosis like many other conditions can vary upon the severity of the disease. Due to the varying locations, size, and patient tolerance the nodules have a wide array of perceived symptoms. Treatment can include observation, padding, change in shoe gear, injections, and ultimately surgical excision. Pentland, et al. reported successful results with monthly intralesional injections of triamcinolone acetonide in a lidocaine suspension over a period of 5 months. Patients reported a smaller and softer lesion that resulted in less pain [15]. The rationale behind the intralesional injection was that the steroids may have an increase in collagenolysis [16]. When the mass becomes too large to undergo injections or conservative therapy has failed and surgery excision becomes warranted there are reports of high recurrence of the mass. Solitary excision of a nodule has shown recurrence rates of $75 \%-100 \%[9,17,18]$. However, when a subtotal fasciectomy is performed the recurrence rates drop to $9.5 \%$ $[19,20]$. Sammarco, et al. recommended at least $1.5 \mathrm{~cm}$ margins [21]. When discussing surgical options, including a subtotal or total plantar fasciectomy, patient will frequently ask if this will give them a flat foot. The plantar fascia has been shown to provide $25 \%$ of passive arch stability [22]. Wapner, et al. found the largest post-operative complication to be a postoperative neuroma followed by delayed wound healing as high as $52 \%$ [23]. Other complications include hematoma, seroma and painful scarring. However, despite multiple potential complications there is an $86 \%$ patient satisfaction rate [21].

\section{Case study}

A case is presented of a 68-year-old male who presented to the clinic with a painful soft tissue mass to the plantar foot. Medical history included chronic obstructive pulmonary disorder, GERD, hypertension, dyslipidemia, and asthma. The patient had no history of cancer, no other fibroproliferative processes, however a positive family history for a mortality secondary to lung and throat cancer. Due to small size of the mass as well as the patient's fear of having the mass excised, conservative therapy was initiated. After a period of 2 years the mass slowly progressed and the patient had difficulty wearing shoes. In preparation for surgery an MRI was obtained (Figures 1-3). The MRI revealed a $6.8 \mathrm{~cm} \times 5.0 \mathrm{~cm} \times 1.5 \mathrm{~cm}$ multinodular mass within the plantar fascia. The mass was mildly heterogeneous in appearance and appeared to be locally invasive to surrounding soft tissue without osseous involvement. Upon incision (Figure 4) a large white glistening fibrotic-appearing multilobulated and smooth mass was seen protruding just over the flexor tendon sheaths of the fourth long flexor and the fifth long flexor, although it did not appear to be violating the actual tendons themselves (Figure 5). The mass encompassed multiple plantar digital nerves. It was also receiving some vascular supply with multiple blood vessels crossing between the multilobulated areas of the mass (Figures 6 and 7). The mass extended plantarly over the entire fifth metatarsal extended medially to the base of the fourth metatarsal (Figure 8) and then it extended dorsally and laterally to the fifth metatarsal shaft (Figure 8). Using Metzenbaum scissors, the mass was freed of all surrounding soft tissue structures. A dorsal incision was made over the fifth metatarsal due to the extension of the mass dorsally (Figure 6). The mass was completely excised and passed from the field to be sent to surgical pathology (Figure 9). The incision was cautiously closed in a layered fashion (Figure 10) with a bulky dressing to bolster the plantar foot to aid in hematoma as well as necrosis prevention. The patient was instructed to remain nonweight bearing for duration of 4 weeks. The patient did however develop a $0.5 \mathrm{~cm}$ linear delay in wound healing that healed uneventfully with local wound care over several

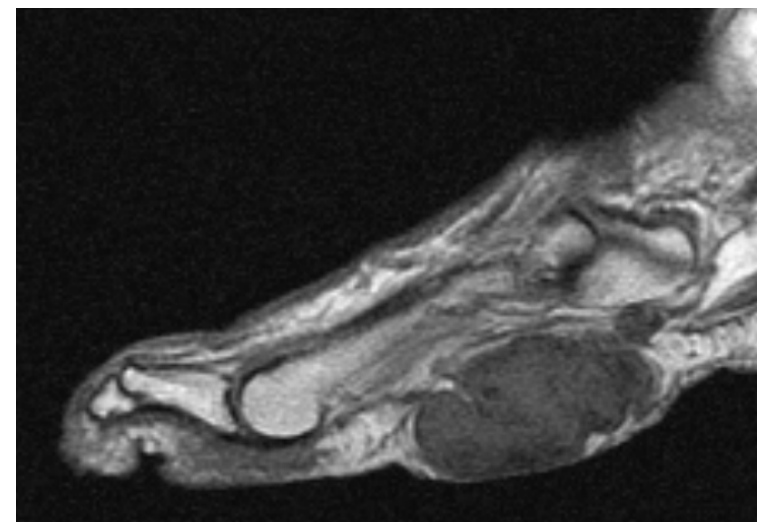

Figure 1. T1 MRI demonstrating a multinodular locally invasive soft tissue mass.

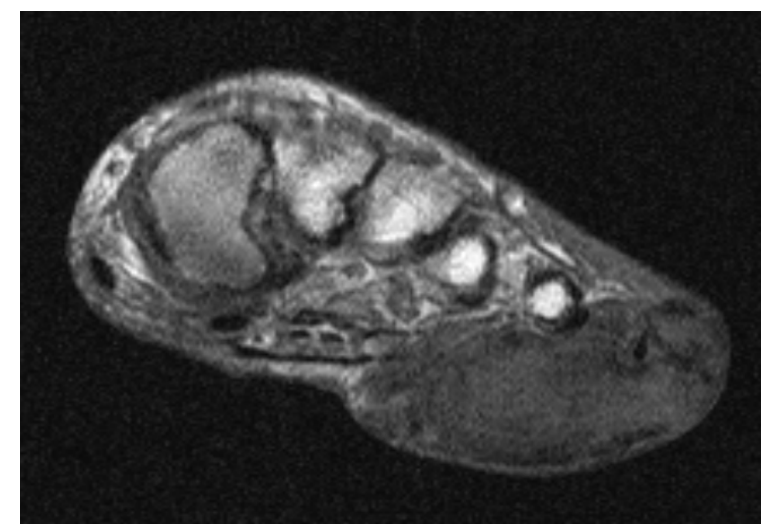

Figure 2. Coronal T1WI of the mass displaying invasion of multiple compartments of the plantar foot.

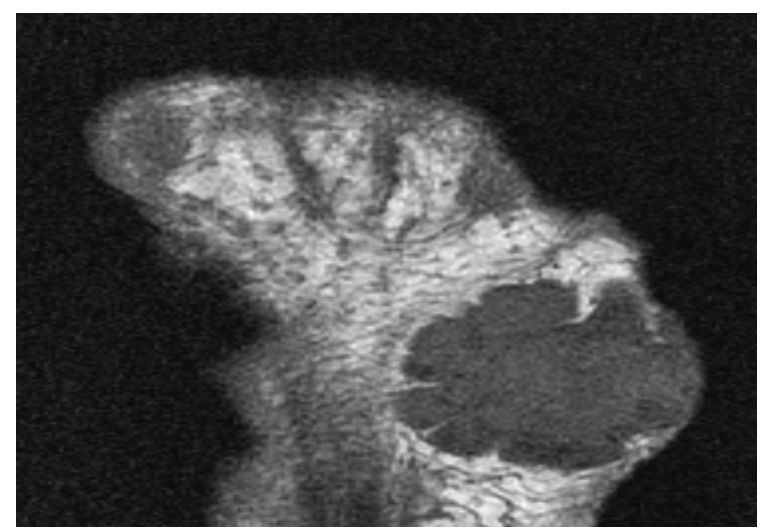

Figure 3. Transvers T1WI demonstrating low signal intensity and homogenous nature of a plantar fibroma. 


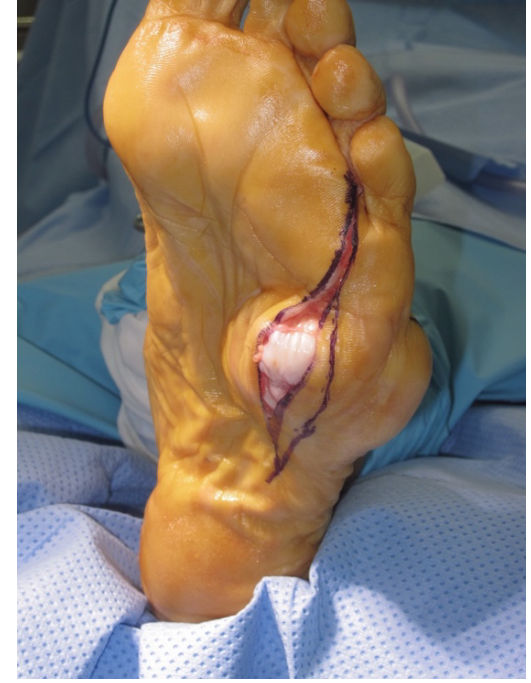

Figure 4. Initial incision demonstrating pressure applied on tissue by mass.

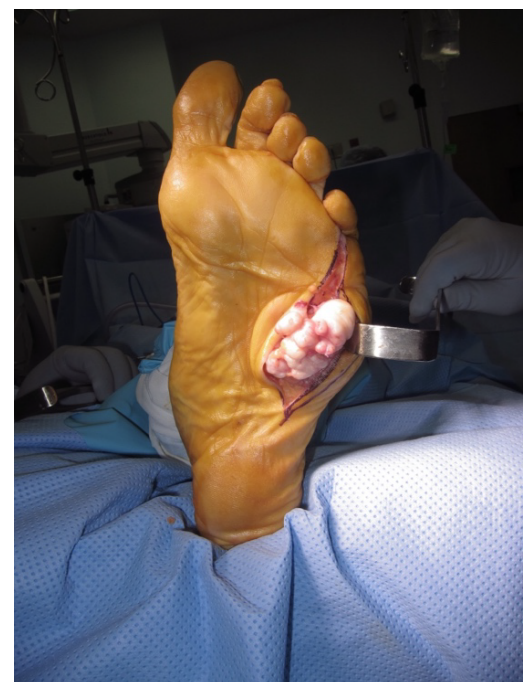

Figure 5. Further dissection of mass displayed an encapsulated and locally infiltrative mass.

weeks. At one year, the patient was discharged from the clinic symptom free ambulating in self-selected shoe gear with custom accommodative inserts.

\section{Pathologic examination}

The specimen was a tan to white lobulated mass. Components of the mass are smooth with firm and soft regions and a bosselated surface. Upon sectioning of the mass was entangled vasculature with no evidence of hemorrhagic necrosis.

From a histological approach the mass will appear with moderate cellularity, fibroblasts, occasional stellate fibroblasts, vessels, inflammatory cells, with foci of hyalinized dense hypocellular collagen [9] These cellular characteristics are the determining factor from differentiating from a more aggressive fibrosarcoma. Beta-catenin immunostaining to confirm the diagnosis microscopically can offer a greater level of patient satisfaction following surgical resection. This stain will show mutations that are consistent with more aggressive biological variants of a deep versus superficial fibromatoses [24].

\section{Discussion}

Plantar fibromas have varying rates of growth which ultimately define treatment. Although the mass can be painless there is a component of discomfort from size and potential for direct nerve compression. Small lesions may be treated conservatively with custom offloading directly under the mass which can prevent upward force to underlying neurovascular structures. Due to the multinodular potential, this may become difficult to offload. Intralesional injections have been shown to decrease firmness and size, however in the authors' opinion, due to the densely-packed collagen fibers it can be difficult to directly administer steroid. Isolated nodular resection has a proven high recurrence rate due to the inability to confidently resect the all cellular components of the highly reproducible mass. Taking $1.5 \mathrm{~cm}$ margins can significantly decrease recurrence, however if recurrence does recur then a total plantar fasciectomy may be warranted. Total plantar fasciectomy has been shown to have the lowest recurrence rates but can also have significant post-operative complications. Incision planning can play a pivotal role in the success of postoperative care.

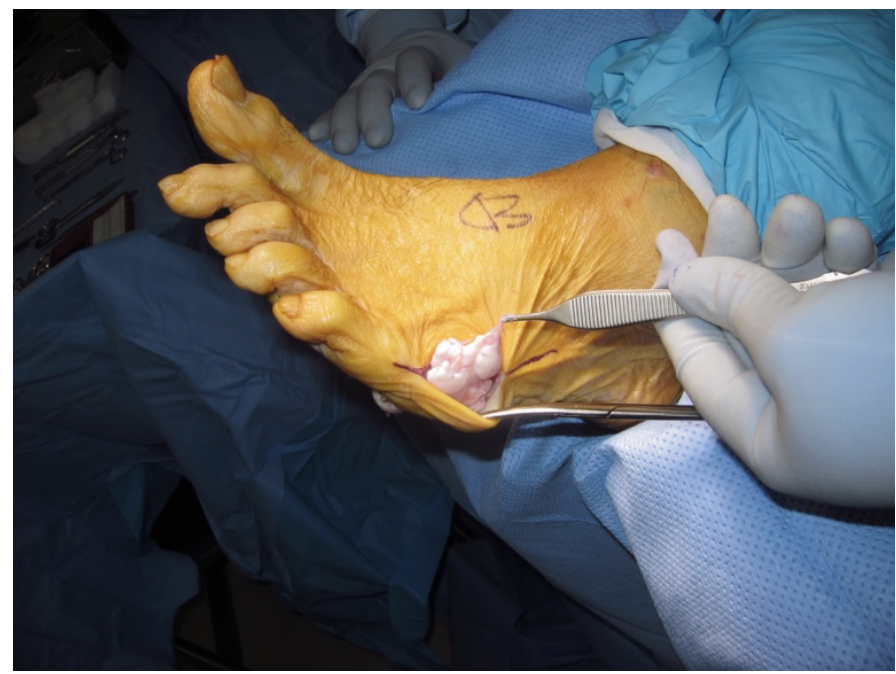

Figure 6. The mass wrapped around the lateral foot expanding into the dorsal space.

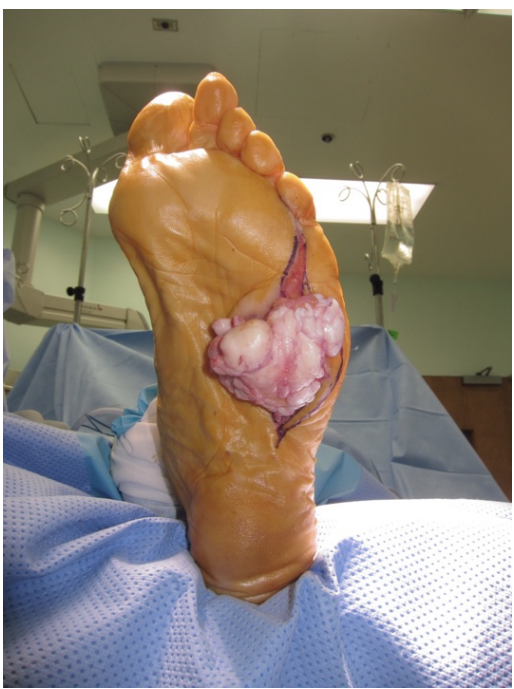

Figure 7. Further dissection of the mass revealing the true size. 


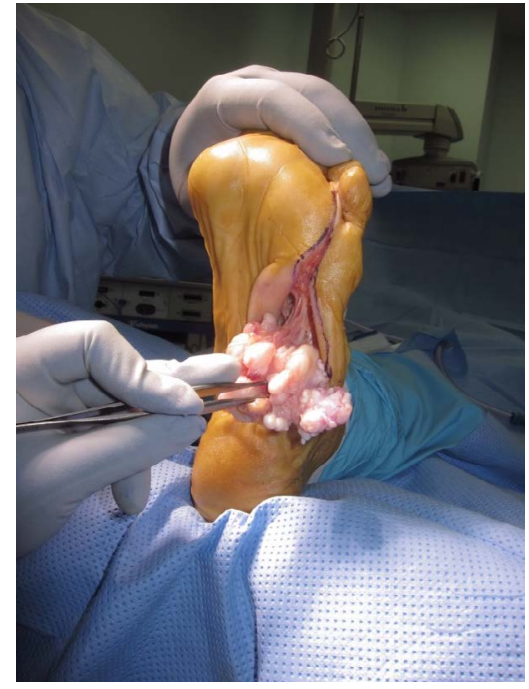

Figure 8. Displaying the invasive nature of the mass and the ability of the mass to spread within the deep compartments of the foot to the intermetatarsal space.

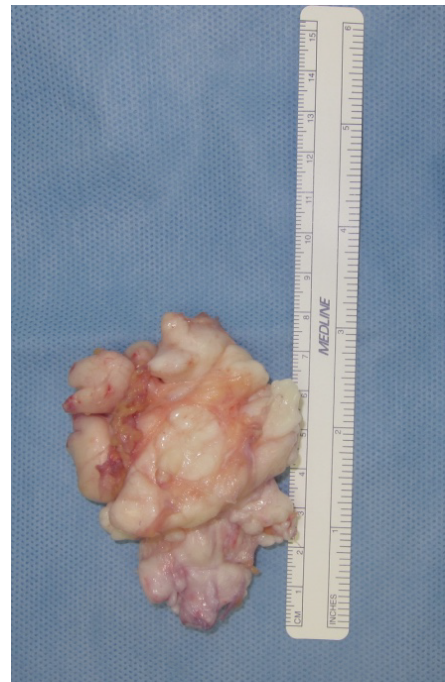

Figure 9. Final mass size upon removal measuring $6.8 \times 5.0 \times 1.5 \mathrm{~cm}$. Displays invasiveness of vascularity.

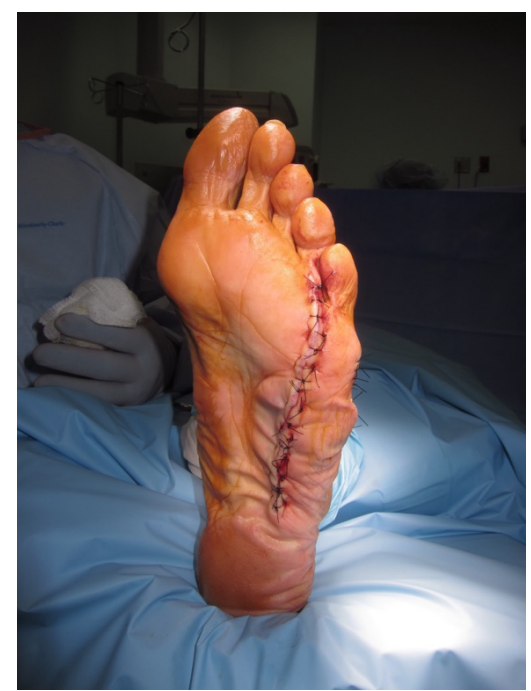

Figure 10. Closed soft tissue following remodeling and resection of extraneous tissue.
Incisional approaches include linear or curvilinear along the medial arch with respect to the plantar foot angiosomes as described by Attinger [25]. An alternative incisional approach has been described as lazy "S", "V" with apex lateral, and multiple "Z". Layered closure can assist in prevention of hematoma, seroma, and soft tissue necrosis. A sterile surgical sponge may be applied as a bolster to apply continuous compression followed by a period of nonweightbearing. For severe neglected deforming masses, amputation as a final surgical option can be considered. The authors strongly believe against this option except in rare cases of severe recalcitrant deformity. Plantar fibromas are a rare soft tissue mass that can affectively be treated surgically as well as conservatively. Patient satisfaction has been reported to achieve $86 \%$ $100 \%$ following surgical resection, therefore proper timely management in combination with accurate histological diagnosis can provide pain relief, deformity correction, and effective overall treatment.

\section{Conflicts of interest}

None.

\section{References}

1. Westerkamp M (1978) A case history of recurrent plantar fibromatosis (Dupuytren's contracture). J Foot Surg 17: 73-74. [Crossref]

2. Madelung OW (1875) Die Aetiologie und die operative Behandlund der Dupuytren $\square$ schen Fingerverkrummung. Berlin Klin Wochenschr 12: 191.

3. Haedicke GJ, Sturim HS (1989) Plantar fibromatosis: an isolated disease. Plast Reconstr Surg 83: 296-300. [Crossref]

4. Gelbard MK, Dorey F, James K (1990) The natural history of Peyronie's disease. $J$ Urol 144: 1376-1379. [Crossref]

5. Cavolo DJ, Sherwood GF (1982) Dupuytren's disease of the plantar fascia. J Foot Surg 21: 12-15. [Crossref]

6. Devries HL (1965) Surgery of the Foot. St. Louis: Mosby. 232-234

7. Ledderhose Georg (1897) Zur pathologie der aponeurose des fusses und der hand.

8. Meyerding HW, Shellito JG (1948) Dupuytren's contracture of the foot. J Int Coll Surg 11: 595-603. [Crossref]

9. Allen PW (1977) The fibromatoses: A clinicopathologic classification based on 140 cases Part 1. The American Journal of Surgical Pathology 1: 255-270.

10. Bauer EA, Cooper TW, Tucker DR, Esterly NB (1980) Phenytoin therapy of recessive dystrophic epidermolysis bullosa: clinical trial and proposed mechanism of action on collagenase. $N$ Engl J Med 303: 776-781. [Crossref]

11. Carnesale PG (1987) Soft tissue tumors. Campbell's Opoerative Orthopaedics, edited by A. H. Crenshaw. Ed 7. Pp. 807-826. St. Louis, C.V. Mosby.

12. Enneking, William F (1983) Musculoskeletal tumor surgery. Churchill Livingstone.

13. Lee TH, Wapner KL, Hecht PJ (1993) Plantar fibromatosis. J Bone Joint Surg Am 75: 1080-1084. [Crossref]

14. Morrison WB, Schweitzer ME, Wapner KL, Lackman RD (1994) Plantar fibromatosis: a benign aggressive neoplasm with a characteristic appearance on MR images. Radiology 193: 841-845. [Crossref]

15. Pentland AP, Anderson TF (1985) Plantar fibromatosis responds to intralesional steroids. J Am Acad Dermatol 12: 212-214. [Crossref]

16. Houck JC, Sharma VK, Patel YM, Gladner JA (1968) Induction of collagenolytic and proteolytic activities by anti-inflammatory drugs in the skin and fibroblast. Biochem Pharmacol 17: 2081-2090. [Crossref]

17. Kashuk KB, Pasternack WA (1981) Aggressive infiltrating plantar fibromatosis. $J$ Am Podiatry Assoc 71: 491. [Crossref]

18. Allen RA, Woolner LB, Ghormley RK (1955) Soft-tissue tumors of the sole; with special reference to plantar fibromatosis. J Bone Joint Surg Am 37-37A: 14-26. [Crossref]

19. Aluisio FV, Mair SD, Hall RL (1996) Plantar fibromatosis: treatment of primary and recurrent lesions and factors associated with recurrence. Foot Ankle Int 17: 672-678. [Crossref] 
20. Enero A, Arlen M, Miller T (1971) Plantar fibromatosis. Plast Reconstr Surg 48: 295.

21. Sammarco GJ, Mangone PG (2000) Classification and treatment of plantar fibromatosis. Foot Ankle Int 21: 563-569. [Crossref]

22. Hedrick MR (1996) The plantar aponeurosis. Foot Ankle Int 17: 646-649. [Crossref]

23. Wapner KL, Ververeli PA, Moore JH Jr, Hecht PJ, Becker CE, et al. (1995) Plantar fibromatosis: a review of primary and recurrent surgical treatment. Foot Ankle Int 16: 548-551. [Crossref]
24. Montgomery E, Lee JH, Abraham SC, Wu TT (2001) Superficial fibromatoses are genetically distinct from deep fibromatoses. Mod Pathol 14: 695-701. [Crossref]

25. Attinger CE, Evans KK, Bulan E, Blume P, Cooper P (2006) Angiosomes of the foot and ankle and clinical implications for limb salvage: reconstruction, incisions, and revascularization. Plast Reconstr Surg 117: 261S-293S. [Crossref]

Copyright: (C2017 Graney CT. This is an open-access article distributed under the terms of the Creative Commons Attribution License, which permits unrestricted use, distribution, and reproduction in any medium, provided the original author and source are credited. 